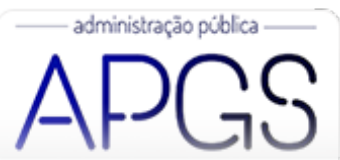

Administração Pública e Gestão Social ISSN: 2175-5787

apgs@ufv.br

Universidade Federal de Viçosa

Brasil

\title{
Dimensões Intraorganizacionais e Funções Gerenciais no Setor Público
}

\author{
de Souza Coelho, Fernando; Lopes Valadares, Josiel \\ Dimensões Intraorganizacionais e Funções Gerenciais no Setor Público \\ Administração Pública e Gestão Social, vol. 11, núm. 4, 2019 \\ Universidade Federal de Viçosa, Brasil \\ Disponível em: http://www.redalyc.org/articulo.oa?id=351560525014
}

Esta obra está bajo una Licencia Creative Commons Atribución-NoComercial-SinDerivar 3.0 Internacional. 


\section{Dimensões Intraorganizacionais e Funções Gerenciais no Setor Público}

Fernando de Souza Coelho

Universidade de São Paulo, Brasil

fernandocoelho@usp.br

Josiel Lopes Valadares

Universidade Federal de Viçosa, Brasil

apgs@ufv.br
Redalyc: http://www.redalyc.org/articulo.oa? $\mathrm{id}=351560525014$

\section{Dimensões Intraorganizacionais e Funções Gerenciais no Setor Público}
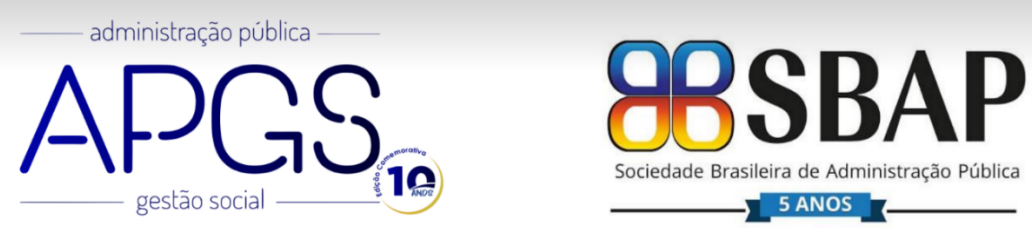

Caros(as) Leitores(as)

Eis a publicação da APGS de outubro-dezembro de 2019, resultado de uma chamada de trabalhos (artigos e casos de ensino) deste periódico com a Sociedade Brasileira de Administração Pública (SBAP); uma edição especial que comemora os 10 anos da revista e os cinco anos da SBAP e cujo edital foi lançado - na ocasião de tal celebração - durante o V Encontro Brasileiro de Administração Pública (EBAP), realizado na Universidade Federal de Viçosa nos dias 13 e 14 de junho de 2018.

Em 10 anos de história, a APGS, de periodicidade trimestral, evoluiu constantemente a sua política editorial e alcançou, na classificação do Qualis/CAPES (2013-2016), o estrato B1 na área de avaliação de Administração Pública e de Empresas, Ciências Contábeis e Turismo, postando-se, destarte, como uma das revistas 'puro sangue' de Administração Pública no Brasil que se sobressaem pela sua importância/qualidade na comunidade acadêmica de Gestão e Políticas Públicas - o chamado "Campo de Públicas" -, pari passu com periódicos como a Revista de Administração Pública (RAP), os Cadernos Gestão Pública e Cidadania (CGPC) e a Revista do Serviço Público (RSP).

Considerando o quão estratégico são essas publicações para a produção científica nacional de Administração Pública, em 2016 a SBAP criou o Fórum de Periódicos de Gestão/Administração Pública, reunindo os editores da APGS, RAP, CGPC e RSP. A iniciativa culminou em ações/atividades de cooperação entre os eventos (como o EBAP) com as revistas, tais como processos de fast tracks de artigos laureados com prêmios nos congressos da SBAP e a organização de edições especiais - como esta que ora apresentamos. ${ }^{[1]}$

Uma vez realizado o acordo entre a APGS e a SBAP, no primeiro trimestre de 2018, para a organização de uma edição especial, coube, na sequência, a definição do tema entre o editor da revista e Diretoria da instituição. Pela alusão à Sociedade Brasileira de Administração Pública, optou-se por retomar a agenda de pesquisa - tradicional - que originou a disciplina de Administração Pública entre o final do século XIX e meados do século XX nos Estados Unidos, qual seja: as dimensões intraorganizacionais e as funções gerenciais no setor público, agora, no século XXI, revalorizando as investigações, com focus administrativo, sobre áreas-meio nos governos e gestão de organizações públicas a partir dos princípios da gestão pública contemporânea como orientação para resultados, foco no usuário-cidadão e interpenetração entre política e 
administração. Ou seja, como descrever e analisar - tecnopoliticamente - os princípios administrativos e a estrutura organizacional no setor público, consagrados desde Woodrow Wilson à Dwight Waldo no passado, como objeto de estudo no presente?

No Brasil, a produção científica sobre as dimensões intraorganizacionais e as funções gerenciais no setor público foi, naturalmente, secundarizada desde os anos 2000, considerando o deslocamento das pesquisas - vis-à-vis a agenda governamental - para o ciclo de políticas públicas (agenda, formulação, implementação e avaliação) e as relações entre Estado-Sociedade pela abordagem sociopolítica da governança pública, caraterizada pela tríade transparência, participação e controle social.

Os artigos publicados em eventos e revistas de Administração/Gestão Pública do país nos últimos 10 anos em tal tema são, comumente, de autoria de practitioners e baseados em estudos de caso que contribuem com a descrição de aplicações administrativo-gerenciais (boas práticas) em áreas-meio de governos e áreasfuncionais de organizações públicas. Todavia, nosso campo do saber carece de ensaios teóricos e artigos teórico-empíricos produzidos por acadêmicos que reflitam sobre os processos administrativos no setor público, atentando-se à triangulação entre o estado da arte da literatura internacional e/ou nacional, à natureza política intrínseca aos problemas públicos e às especificidades da gestão pública brasileira.

Haja vista essa lacuna doméstica na pesquisa de Administração Pública, a chamada de trabalhos foi elaborada para convidar/acolher artigos que se enquadrassem na tradição de gerenciamento no setor público, compreendendo a gestão como política pública (ou, dito de outra forma, as políticas públicas de gestão), sem incorrer no mimetismo de gestão empresarial - na acepção de business administration -- e na discussão simplista e meramente instrumental de ferramentas/práticas gerenciais descontextualizadas dos constrangimentos políticos, jurídicos e técnicos da public administration. $\mathrm{O}$ quadro 1 , abaixo, especifica os tópicos - tal como uma lista de assuntos/conteúdos - constantes do edital desta edição especial.

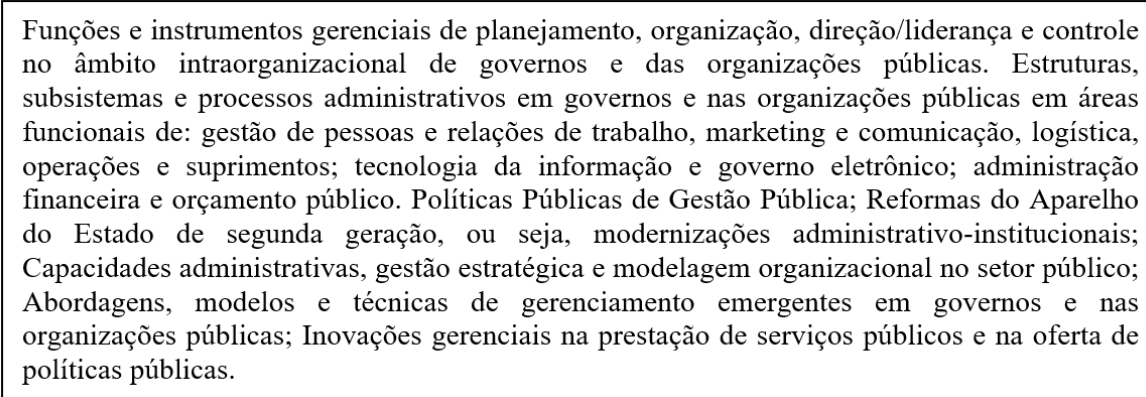

Quadro 1 - Tópicos Sugeridos para esta Edição Especial da APGS com a SBAP

Para qualificar esta edição especial, concernente à valorização da chamada de trabalhos perante a comunidade acadêmica de Administração Pública do país e, sobretudo, no tocante ao processo editorial (desk review, peer review e seleção dos artigos para publicação), convidamos 4 (quatro) professores, de distintas instituições e com diferentes expertises sobre a gestão pública brasileira, para coeditarem a publicação, quais sejam:

- Prof. Dr. Bianor Scelza Cavalcanti - Diretor Internacional da Fundação Getulio Vargas (FGV) e membro do board editorial da Public Administration Review (PAR). Doutor em Public Administration and Policy pela Virginia Polytechnic Institute and State University e mestre em Public Administration pela University of Southern California. Foi diretor da EBAPE-FGV, editor da RAP, coordenador da área de Administração Pública da ANPAD, presidente da Rede Interamericana de Educação em Administração Pública (INPAE) e presidente da International Association of Schools and Institutes of Administration (IASIA);

- Prof. Dr. Dany Flávio Tonelli - Professor de Administração Pública da Universidade Federal de Lavras (UFLA) e, atualmente, pró-reitor adjunto de Extensão e Cultura nesta universidade. Doutor e 
mestre em Administração pela UFLA. Foi professor visitante no Research Institute of the University of Bucharest na Romênia. Laureado com os prêmios de menção honrosa do Emerald/CLADEA Management Research Fund Award (2017), bem como de melhor artigo do Simpósio de Gestão da Inovação Tecnológica da ANPAD (2008) e do Simpósio de Engenharia de Produção - SIMPEP (2007);

- Prof. Dra. Evelyn Levy - Presidente do Comitê Científico do Congresso Consad de Gestão Pública. Doutora em Administração e mestre em Administração Pública e Governo pela EAESP-FGV. Foi diretora da Escola Nacional de Administração Pública (ENAP), secretária de Gestão Pública do Ministério do Planejamento, Orçamento e Gestão (MPOG), subsecretária de Gestão Pública do Estado de São Paulo, professora de Administração Pública da EACH-USP, consultora sênior do Banco Mundial e editora da revista Espaço \& Debates;

- Prof. Dr. Thiago Ferreira Dias - Professor de Administração Pública da Universidade Federal do Rio Grande do Norte (UFRN) e líder de tema da Divisão Acadêmica de Administração Pública da ANPAD. Doutor em Administração pela UFRN e mestre em Administração e Desenvolvimento Rural pela Universidade Federal Rural de Pernambuco (UFRPE). Foi vice-presidente da SBAP (2016-2018), coordenador do Curso de Mestrado Profissional em Gestão Pública da UFRN (2014-2017) e editor adjunto - como membro do conselho científico - da Revista do Serviço Público (RSP).

Com essa equipe editorial de especialistas em Administração Pública, e com o apoio do staff administrativo da APGS, após o lançamento da chamada de trabalhos no V EBAP, levou-se a cabo a divulgação do edital durante o segundo semestre de 2018, alcançando acadêmicos dos programas de pós-graduação e institutos de pesquisa em Gestão Pública pelos mailings da SBAP, APGS, ANPAD, RGS, PROFIAP, Campo de Públicas e GIGAPP, além de técnicos de órgãos públicos das redes do CONSAD e das escolas de governo da ENAP. A submissão dos trabalhos encerrou-se no dia 31 de janeiro deste ano e, satisfatoriamente, recebemos 75 artigos oriundos de todas as regiões administrativas do país (e um do exterior) e com autores vinculados a 58 organizações - entre instituições de ensino e pesquisa, órgãos públicos e entidades do terceiro setor.

Pelo volume de artigos submetidos para esta edição especial, urgia, em fevereiro, iniciar o processo de avaliação. A primeira fase da avaliação foi realizada pelo editor e coeditores convidados entre o dia $1^{\circ}$ de fevereiro e o dia 31 de março. Alcunhada como desk review, essa etapa baseou-se em uma triagem - diligente e minuciosa - dos trabalhos que sopesou três análises, a saber:

- Análise de formatação dos textos em relação às normas da APGS - vide o link https:// periodicos.ufv.br/ojs/apgs/about/submissions\#authorGuidelines;

- Análise de aderência dos manuscritos ao descritor da chamada de trabalhos - de acordo com os tópicos sugeridos supramencionados no quadro 1 ;

- Análise de potencial de contribuição teórica e/ou empírica dos artigos à luz do padrão de produção científica qualificada de um periódico B1 no Sistema Qualis/CAPES na área de avaliação de Administração Pública e de Empresas, Ciências Contábeis e Turismo.

Assim, esse primeiro ciclo avaliativo seguiu essa ordem, isto é: preliminarmente foi averiguada a adequação de forma dos documentos; na sequência, para os trabalhos aprovados na formatação efetuouse, então, a verificação de aderência dos textos com os assuntos/conteúdos abarcados pelas Dimensões Intraorganizacionais e Funções Gerenciais no Setor Público; e, finalmente, para os artigos julgados aderentes ao tema da edição especial procedeu-se a análise de potencial científico.

Amiúde, trabalhos que tomaram as organizações públicas somente como locus de estudo, mas não mobilizaram a literatura de Administração/Gestão Pública pelo focus administrativo como lente analítica, foram classificados como não aderentes e, portanto, rejeitados no desk review. E, via de regra, todos os artigos 
aprovados no crivo da aderência, mas que estavam com o referencial teórico subdesenvolvido, com falhas metodológicas e/ou com a análise dos resultados inacabada e que, portanto, iria requerer um amplo e/ou profundo esforço de revisão do(s) autor(es), foram - igualmente - rejeitados no desk review. ${ }^{[2]}$

Em abril, ao anunciarmos o resultado do desk review para os autores, apurou-se que: todos os 75 textos foram aprovados na análise de formatação; na análise de aderência, por sua vez, foram aprovados 49 manuscritos e reprovados 26; e, enfim, na análise de potencial científico foram aprovados 12 artigos dos 49 avaliados (portanto, 37 trabalhos foram recusados). ${ }^{[3]}$ Cabe mencionar que os autores dos 63 rejeitados nas fases de análise de aderência e análise de potencial científico receberam um parecer, por e-mail, com a explanação do motivo pelo qual o trabalho foi recusado em uma dessas etapas do processo de desk review.

Com 12 artigos aprovados para a segunda fase da avaliação, a chamada peer review, nós convidamos 16 avaliadores - doutores e com experiência nas temáticas dos manuscritos em análise - para, em conjunto com o editor e os coeditores, realizarem a etapa de double blind review dos trabalhos, executada nos meses de maio e junho. A seguir, o quadro 2 elenca o nome e filiação institucional desses colegas, professores e pesquisadores da comunidade acadêmica de Administração Pública, a quem agradecemos pela generosa e esmerada colaboração como pareceristas ad hoc.

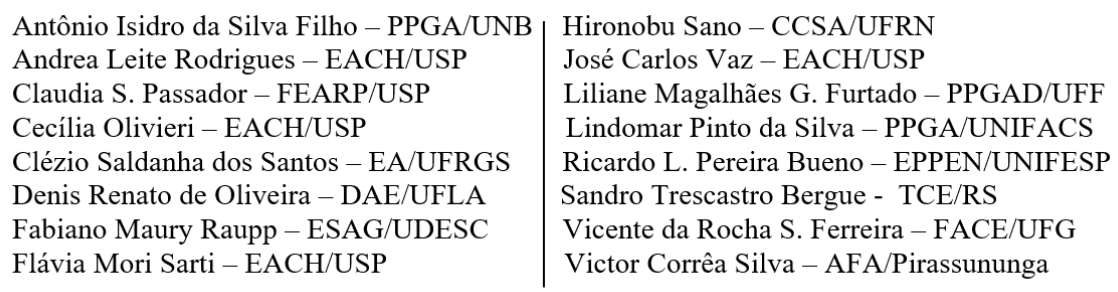

Victor Corrêa Silva - AFA/Pirassununga

\section{Quadro 2 - Nominata de Avaliadores desta Edição Especial da APGS com a SBAP}

Após recebermos a avaliação dos 12 artigos, nós lemos todos os pareceres e tomamos - coletivamente uma decisão editorial, escolhendo os 9 (nove) artigos com escore de avaliação para aprovação entre os 12 trabalhos avaliados nesta segunda fase.

Em meados de junho, com as avaliações dos 12 artigos concluídas no sistema de editoração da APGS, o editor e os coeditores leram todos os pareceres e tomaram coletivamente uma decisão editorial, aprovando os 9 (nove) artigos com escore de avaliação admissível - mediante modificações minor - entre os 12 trabalhos examinados nesta segunda fase. As correções obrigatórias, solicitadas pelos pareceristas, foram informadas para os autores que, durante o mês de julho, realizaram os ajustes em seus textos e submeteram a versão final para a revista. Após a reanálise do editor e dos coeditores, os 9 (nove) artigos foram, definitivamente, aceitos para publicação, dado que cumpriram as devidas modificações.

Encerrando esse itinerário editorial de 18 meses - encetado com a idealização desta edição especial no primeiro trimestre de 2018 -, nos últimos 60 dias (agosto e setembro de 2019) os artigos aceitos para publicação passaram pelo processo editorial de revisão ortográfica, diagramação textual e indexação nas 22 bases da APGS, originando, assim, esse número da APGS com a SBAP que, em seguida, prefaciamos.

Resta-nos como desfecho deste editorial agradecer o prestígio dos(as) autores(as) e, novamente, reconhecer o imprescindível auxílio acadêmico dos 4 (quatro) coeditores e 16 avaliadores. Em suma, nosso muito obrigado a todos(as)!

\section{Prefácio da Edição Especial da APGS com a SBAP: aPresentaÇÃo dos artigos}

O rol de artigos publicados nesta edição especial exprime as variadas temáticas envoltas com a tônica das Dimensões Intraorganizacionais e Funções Gerenciais no Setor Público como: gestão pública baseada em 
evidências, burocracia e performance, desempenho/eficiência de organizações públicas, comportamento organizacional na administração pública, gestão de recursos humanos no governo, inovação na gestão pública, gestão de políticas públicas, controle patrimonial em órgãos públicos e processo de compras públicas. E abarcam desde ensaios teóricos até artigos teórico-empíricos, qualitativos e quantitativos, cujos objetos de estudo compreendem organizações e/ou políticas públicas nos três níveis de governo no Brasil, além de um case internacional.

Os 9 (nove) trabalhos têm, agregadamente, 19 autores que representam 10 organizações entre programas de pós-graduação e escolas de governo, sendo duas da região Sul, três da região Sudeste, duas da região Nordeste, duas da região Centro-Oeste e uma do exterior - Espanha. Antes, porém, de apresentar sumariamente cada um dos textos, evidenciamos o artigo convidado desta edição especial, resultado de uma cooperação internacional de um renomado professor - em nível mundial - de public management da London School of Economics and Political Science (LSE) com a Escola Nacional de Administração Pública (ENAP).

Intitulado "Inovando no Desenvolvimento de Profissionais da Gestão Pública: o caso do Programa de Desenvolvimento de Lideranças da Escola Nacional de Administração Pública”, o artigo convidado, de autoria do Prof. Michael Barzelay com os colegas - brasileiros - Humberto Falcão Martins, Pedro Vilela e Paulo Marques, apresenta uma nova abordagem, na forma e no conteúdo, de lapidar o exercício profissional de gestores públicos orientada por design, baseada nas ideias do livro recém-lançado (Public Management as a Design-Oriented Professional Discipline) pelo docente da LSE, as quais foram aplicadas em um programa de T\&D na ENAP no triênio 2016-2019.

Concernente aos trabalhos aceitos para publicação no fluxo de avaliação, o artigo 1, "Capacidades Analíticas no Processo de Produção de Políticas Públicas: Quais Fontes de Evidências Usam os Burocratas do Serviço Civil da Administração Pública Federal?”, escrito por Alex Santos Macedo, Rafael Viana e Maricilene Isaira Baia do Nascimento, desvela como os servidores públicos da União - a partir de informações de 2000 burocratas - usam evidências para formularem/gerirem políticas públicas. Em uma época de wicked problems na gestão governamental, mas, paradoxalmente, de desinformações e ausência de embasamento científico-tecnológico na agenda política, é oportuno esse texto para refletirmos sobre a abordagem da evidence-based policy making no setor público brasileiro.

O artigo 2, "Qualidade Burocrática e Performance Estatal: Desvendando a Caixa Preta do Município", elaborado por André Luis Rabelo Cardoso e André Marenco, investiga, a partir de uma análise fatorial de dados da Munic/IBGE, como a qualidade da burocracia local afeta os indicadores socioeconômicos dos municípios. Essa agenda de pesquisa sobre capacidades estatais na gestão pública municipal, no Brasil, justapondo a Ciência Política com a Administração Pública, é apropriada para se (re)pensar - e fortalecer - o modus operandi das prefeituras no nosso federalismo, decorridos 30 anos da Constituição Federal de 1988.

O artigo 3, "Hospitais de Alta Complexidade do estado de São Paulo: Uma Análise Comparativa dos Níveis de Eficiência Obtidos pelos Modelos de Gestão de Administração Direta e de Organização Social”, redigido por Diego Pugliese Tonelotto, Patricia Righetto, Vinicius Macedo de Moraes e Jaime Crozatti, utiliza-se da análise envoltória de dados para comparar, exploratoriamente, a performance de hospitais administrados pelo governo com os equipamentos geridos por OSs. Trata-se de uma pesquisa que contribui para jogar luz - para além de discursos ex-ante pró ou contra a publicização da prestação de serviços públicos - sobre o uso de recursos públicos por organizações públicas estatais e não-estatais de saúde no ambiente de competição administrada estimulado pela Reforma Gerencial de 1995.

O artigo 4, "Consequentes de Motivação do Serviço Público: Proposição de um Framework de Análise em Organizações Públicas Brasileiras”, de Jefferson Menezes de Oliveira e Vania de Fátima Barros Estivalete, sugere um modelo de motivação do serviço público para se estudar a percepção de congruência de valores entre indivíduo e organização no setor público brasileiro. $\mathrm{O}$ trabalho é oriundo de um working paper, apresentado e publicado nos anais do XLII EnANPAD, realizado em 2018, sendo um dos três artigos - 
na ocasião - indicados ao prêmio da Divisão Acadêmica de Administração Pública (APB). Um texto que incentiva o front de investigação sobre comportamento organizacional na nossa Administração Pública.

O artigo 5, "Retos de Futuro en la Gestión de los Recursos Humanos Públicos en España”, de Carmen Pineda Nebot, apresenta a experiência espanhola de política de gestão de pessoas no governo - um caso ibérico que tem potencial de análise comparativa com a realidade brasileira, sendo, portanto, uma contribuição para a literatura doméstica de recursos humanos no setor público. Em conjunto com o artigo convidado, que tem a coautoria de um professor estrangeiro, esse trabalho simboliza a parcela de internacionalização desta edição especial da APGS com a SBAP.

O artigo 6, "Inovação na Gestão Pública como 'Possibilidade Objetiva': O Caso do Pacto pela Educação de Pernambuco sob a Ótica da Administração para o Desenvolvimento”, procedente da dissertação de mestrado de Jessica Rani Sousa no PROPAD/UFPE, emprega o arcabouço teórico de Alberto Guerreiro Ramos para observar práticas efetivas/transformadoras na política pública de educação. Gradativamente, as obras de Guerreiro Ramos são (re)descobertas pelos acadêmicos nacionais (e internacionais) para a análise organizacional no pensamento administrativo, englobando a gestão pública.

O artigo 7, "Dimensões Estatal, Gerencial e Individual da Política Nacional de Prevenção e Controle do Câncer de Mama: um Modelo Avaliativo", de autoria de Daiane Medeiros Roque Ferreira, Afonso Augusto Teixeira de Freitas de Carvalho Lima e Marco Aurélio Marques Ferreira, assinala a existência de três dimensões teóricas condicionantes do desempenho de tal política e aventa um arquétipo para avaliá-la. O trabalho é derivado da tese de doutorado da primeira autora, defendida no Programa de Pós-Graduação em Administração da Universidade Federal de Viçosa (2018) e vencedora do Prêmio SBAP de Melhor Tese de Doutorado em Administração Pública - edição 2019.

O artigo 8, "Análise do Controle Patrimonial de Bens Permanentes em uma Organização Pública", assinado por Elizabeth Carvalho Fernandes e Doraliza Monteiro, descreve e analisa - didaticamente - como como ocorre a gestão patrimonial no setor público, tendo como locus uma instituição de educação pública. O controle patrimonial é objeto de estudo (e aplicação) na Administração Pública brasileira desde a criação do Departamento Administrativo do Serviço Público (DASP) em 1938. Sem embargo, seu conteúdo é, historicamente, secundarizado pela academia de Gestão Pública no país, sendo tratado mais comumente pelo Direito Financeiro e pela Contabilidade Pública. Logo, é fulcral que se valorize os textos que, como este artigo, intentam uma perspectiva administrativa dessa função gerencial.

E por último, mas não menos importante, o artigo 9, "Compras Públicas no Brasil: Vertentes de Inovação, Avanços e Dificuldades no Período Recente”, de Ciro Campos Christo Fernandes, faz um balanço do gerenciamento de compras públicas no Brasil, a partir do levantamento e categorização dos trabalhos do Congresso CONSAD de Gestão Pública - o maior evento de practtioners do setor público no país. Em linhas gerais, o manuscrito espelha as diversas vertentes técnicas de aplicação do instituto de licitações e de suprimentos na gestão governamental.

Ademais, para completar a publicação, encomendamos aos 4 (quatro) coeditores alguns documentos para ampliar as contribuições desta edição especial para a nossa comunidade acadêmica de Administração/Gestão Pública. Assim, o volume é rematado com:

- Uma pensata sobre as conquistas recentes e os dilemas presentes na gestão pública brasileira, escrita pela Prof. Evelyn Levy;

- Um informe sobre a internacionalização, como desafio e oportunidade, das escolas, institutos e programas de pós-graduação de Administração Pública brasileiros, redigido pelo Prof. Bianor Cavalcanti;

- Uma apresentação da recém-lançada coleção de livros de Gestão Pública da SBAP com a ENAP, de autoria do Prof. Thiago Dias;

- Uma resenha de obra sobre Inovação e Gestão Pública, lançada pelo IPEA no primeiro semestre deste ano, compendiada pelo Prof. Dany Tonelli. 
À guisa de conclusão, esperamos que apreciem a leitura desta edição especial da revista Administração Pública e Gestão Social em parceria com a Sociedade Brasileira de Administração Pública. E, aproveitando o ensejo desta publicação referir-se aos 10 anos da APGS e aos 5 (cinco) anos da SBAP, nossos desejos de vida longa a ambas as instituições em prol do fortalecimento da Administração/Gestão Pública como área de conhecimento - de ensino, pesquisa e extensão - no Brasil.

\section{Notas}

1 Para um compêndio do lustro da Sociedade Brasileira de Administração Pública entre 2013 e 2018 e seu arrolamento de realizações nesse período, acesse o documento de apresentação institucional e o relatório de gestão da Diretoria da SBAP (2016-2018), disponível pelo link: https://rive.google.com/file/d/1USeNFkKvvQOhVldZzq1Vl14lIqcWAnUa/ view?fbclid=IwAR0P-qQqnFaRDEqa35su4MJEbT8YkQCQGDBeHYaLwVhlNXrfzmJBA4qVTP8

2 Vale salientar que a rejeição do trabalho na etapa de aderência não tem relação com o potencial científico do artigo, uma vez que a análise de contribuição teórica e/ou empírica foi efetuada apenas para os manuscritos aprovados previamente na verificação de aderência. Posto isto, nós - editor e coeditores - recomendamos, na devolutiva ao(s) autor(es) de cada trabalho, que ele $(\mathrm{s})$ considerasse $(\mathrm{m})$, ulteriormente, escolher $(\mathrm{em})$ um periódico cujo escopo editorial fosse mais condizente com a proposta e os aportes científicos do texto.

3 Cabe salientar que a rejeição na análise de potencial científico arbitrou a versão submetida do artigo em face das contribuições esperadas de um trabalho publicado em uma revista classificada no estrato mais alto (B1, A2 e A1) do Qualis/CAPES. Ou seja, os artigos recusados podem tanto ser aperfeiçoados para uma nova submissão para periódicos do mesmo estrato (incluindo a própria APGS num futuro próximo), bem como podem ser redirecionados para revistas do estrato intermediário (B2, B3 e B4), cujos critérios de avaliação não são tão exigentes e/ou o processo de desk review é menos competitivo. Essa sugestão foi dada no feedback - por correio eletrônico - para os autores dos artigos recusados nessa etapa.

\section{BY-NC-ND}

